\section{Antibacterial effects of the methanolic extract of Glycine Max (Soybean)}

\author{
Seyede Asma Hosseini Chaleshtori, ${ }^{1}$ \\ Mehrdad Ataie Kachoie, ${ }^{1}$ \\ Seyed Mojtaba Hashemi Jazi ${ }^{2}$ \\ ${ }^{1}$ Department of Agro-ecology, Faculty of \\ Agriculture, Shahrekord Branch, \\ Islamic Azad University, Shareakord; \\ ${ }^{2}$ Horticulture Crop Research \\ Department, Chaharmahal Va \\ Bakhtiari, Agricultural and Natural \\ Resources, Research and Education \\ Center (AREEO), Shahrekord, Iran
}

\begin{abstract}
High occurrence of antibiotic resistance in pathogenic bacteria is caused by the use of natural medicinal plants to eliminate risk of infectious diseases. Glycine max is on the most popular and nutritious foods with high antimicrobial effects. The present research was done to study the antibacterial effects of the methanolic extract of $G$. max against Gram-negative and positive bacteria. $G$. max seeds of M7 and M9 varieties were purchased and their methanolic extracts were collected. Diameter of the zone of growth inhibition of extracts were measured for pathogenic bacteria using the CLSI guidelines. Antimicrobial effects of G. $\max$ extracts were also compared with several antibiotics. Diameter of the inhibition zone of tested bacteria against different treatments of $G$. max had a ranges of $5.93 \pm 0.18$ to $22.61 \pm 1.80 \mathrm{~mm}$. M7 variety had a higher antimicrobial effects on tested bacteria $(\mathrm{P}<0.05)$. The highest diameter of the zone of growth inhibition was seen for L. monocytogenes $(22.61 \pm 1.80 \mathrm{~mm})$ and $S$. aureus $(19.33 \pm 1.56 \mathrm{~mm})$. Antimicrobial effects of the methanolic extract of the G. max was also dose-dependent $(\mathrm{P}<0.05)$. Diameter of the inhibition zone of tested bacteria against different antibiotic agents had a ranges of $5.94 \pm 0.38$ to $24.95 \pm 2.11 \mathrm{~mm}$. Ciprofloxacin, penicillin $\mathrm{G}$ tetracycline, gentamicin and azithromycin antibiotic agents exhibited the highest diameter of zone of the growth inhibition for $K$. pneumoniae $(15.71 \pm 1.46 \mathrm{~mm})$, L. monocytogenes $(23.94 \pm 2.03 \mathrm{~mm})$, L. monocytogenes $(20.55 \pm 1.95 \mathrm{~mm}), S$. aureus $(14.27 \pm 1.36$ $\mathrm{mm}$ ) and L. monocytogenes $(24.95 \pm 2.11$ $\mathrm{mm}$ ), respectively. Formulation of antibiotic agent using the $100 \mathrm{mg} / \mathrm{mL}$ concentration of the M7 variety of G. $\max$ has been recommended for treatment of the cases of infectious diseases.
\end{abstract}

\section{Introduction}

In spite of the considerable progress of medicine, treatment of infectious diseases faced with different unfavorable problems. Occurrence of severe levels of the antibiotic resistance is the main issue facing medical practitioners. ${ }^{1,2}$ Antimicrobial resistance threatens the effective prevention and treatment of an ever-increasing range of infections caused by bacteria. It is an increasingly serious threat with global public health impact that requires action across all government sectors and society. ${ }^{3,4}$ Resistant bacteria caused more severe clinical diseases for longer period of time which causes abundant economic losses. ${ }^{1-4}$ Documented data revealed that pathogenic bacteria and especially Staphylococcus aureus ( $S$. aureus), Escherichia coli (E. coli), Bacillus cereus (B. cereus), Pseudomonas aeruginosa (P. aeruginosa), Listeria monocytogenes (L. monocytogenes), Klebsiella pneumoniae (K. pneumoniae) and Salmonella typhi (S. typhi) exhibited the high levels of resistance against aminoglycosides, tetracyclines, lincosamides, macrolides, beta-lactams, quinolones, fluoroquinolone and cephems groups of antibiotics. ${ }^{1-8}$ Therefore, therapeutic and pharmacological factories tried to use from novel sources for antimicrobial agents to produce strong antibiotic drugs. Application of medicinal plants for producing of antimicrobial agents had an ancient history. ${ }^{9}$ Soybean (Glycine $\max (G$. $\max )$ ) belongs to a large botanical family Leguminosae which classically grows in tropical, subtropical and temperate climatic regions like Iran. ${ }^{10}$ Soybean is an oilseed and consists of $20 \%$ oil content. It is considered as the most significant crop for the production of edible oil. Soybean plant holds great importance in today's world mainly because of its high protein and lipid content and other major constituents including vitamins, minerals, fatty acids and other essential nutritional factors. ${ }^{10-12}$ Besides. soybean holds much importance from medicinal perspective. Recorded data revealed the high antimicrobial and antioxidant content of the G. $\max ^{10-12}$ Soybean seeds are rich in proteins, isoflavones and phytoestrogens, while Genistein, a soy isoflavone, has also been reported to possess anti-cancerous, antioxidant, anti-inflammatory and anti-osteoporosis effects and is considered as potential compound for metabolic disorders' treatment. ${ }^{10-12}$

According to the uncertain antimicrobial effects of the G. $\max$, the present investigation was done to study the antibacterial effects of the methanolic extract of the M7 and M9 varieties of the G. $\max$ on Gramnegative and positive bacteria.
Correspondence: Dr. Mehrdad Ataie Kachoie, Department of Agro-ecology, Faculty of Agriculture, Shahrekord Branch, Islamic Azad University, Shareakord, Iran.

Tel.: +98.913.1197568

E-mail:mehrdad.ataie@gmail.com

Key words: Glycine max, Methanolic extract, Antimicrobial effect, Zone of growth inhibition.

Acknowledgements: the authors would like to thank Prof. Ebrahim Rahimi at the Islamic Azad University of Shahrekord, Shahrekord Iran for their important technical support. This work was supported by the Islamic Azad University, Shahrekord Branch, Shahrekord, Iran (Grant No. 96/145)

Contributions: the authors contributed equally

Conflict of interest: the authors declare no potential conflict of interest.

Received for publication: 19 July 2017.

Accepted for publication: 31 July 2017.

This work is licensed under a Creative Commons Attribution NonCommercial 4.0 License (CC BY-NC 4.0).

(C) Copyright S.A. Hosseini Chaleshtori et al., 2017 Licensee PAGEPress, Italy

Microbiology Research 2017; 8:7319

doi:10.4081/mr.2017.7319

\section{Materials and Methods}

\section{Ethical issues}

The study was approved by the Ethical Council of Research of the Faculty of Agriculture and Food Sciences, Shahrekord Branch, Islamic Azad University, Shahrekord, Iran (Consent Ref Number 96-176). Verification of this research project and the licenses related to sampling process were approved by Mehrdad Ataie Kachoie and Prof. Ebrahim Rahimi (Approval Ref Number Agrtic 2016/28).

\section{Samples}

Two different seed varieties of $G$. $\max$ mutant of Clark (M7 and M9) were obtained from the National Agriculture Research Centre of Isfahan province, Iran. Samples were collected in sterile polyethylene bags. These two varieties of $G$. $\max$ were tested for their antibacterial activity. The fresh seeds were dried under shade. Weighed around 10 gram of soybeans seed and washed air, dried at room temperature and coarsely powdered in a mixer sieved. Dried seeds were disinfected with $15 \%$ $\mathrm{H} 2 \mathrm{O} 2$ and stored at room temperature in sterile sealed bottled until its extraction. 


\section{Methanolic extract}

For the preparation of methanol extracts, $50 \mathrm{~g}$ of each seed sample was dissolved in $500 \mathrm{~mL}$ of methanol solvents. After dissolution, each sample was placed in shaking incubator at moderate temperature of $37^{\circ} \mathrm{C} \pm 2$ for 7 days. After 7 days, the samples were taken out of shaker and filtered initially with muslin cloth and then with Whatman filter paper \#01 (11 $\mu \mathrm{m})$ so that transparent solution was obtained. The filtrates obtained were then placed in water bath at moderate temperature of $35^{\circ} \mathrm{C} \pm 2$ for 6-7 h daily until dried extracts were obtained.

\section{Microorganisms used and growth conditions}

Strains of bacteria selected to assess susceptibility pattern were Bacillus cereus (ATCC 10987), Escherichia coli (ATCC 8739), Pseudomonas aeruginosa (ATCC 27853), Staphylococcus aureus (ATCC 6538), Listeria monocytogenes (ATCC 19111), Klebsiella pneumoniae (ATCC 43816) and Salmonella typhi (ATCC 14028). Bacterial cultures were purchased from the Pasteur Institute of Iran. Each microorganism was reactivated prior to susceptibility testing by transferring them into a separate test tubes containing nutrient broth (NB, Merck, Germany) and incubated overnight at $37^{\circ} \mathrm{C}$ at shaker.

\section{Antibacterial effects of $G$. $\max$}

Guidelines of the Clinical and Laboratory Standard Institute (CLSI) were used to study the antibacterial effects of $G$. $\max$ M7 and M9 methanolic extracts. ${ }^{13}$ Simple disk diffusion method was used to study the diameter of zone of inhibition of several types of bacteria subjected to 25 $\mathrm{mg} / \mathrm{mL}, 50 \mathrm{mg} / \mathrm{mL}$ and $100 \mathrm{mg} / \mathrm{mL}$ concentrations of G. $\max \mathrm{M} 7$ and M9 methanolic extracts. Paper discs (Whatman No $6 \mathrm{~mm}$ diameter) were separately impregnated with aliquots of $10 \mu \mathrm{L}$ of each concentration of the G. $\max$ M7 and M9 extracts and placed onto the seeded top layer of the inoculated MHA plates. Findings of the antibacterial effects of the G. $\max$ extracts were compared with several types of antibiotic agents including ciprofloxacin (5 $\mu \mathrm{g} /$ disk), penicillin $\mathrm{G}$ (10 u/disk), tetracycline (30 $\mu \mathrm{g} /$ disk $)$, gentamicin (10 $\mu \mathrm{g} /$ disk $)$ and azithromycin (15 $\mu \mathrm{g} /$ disk) (Oxoid, UK). Bacterial strains were spread on to Muller Hinton Agar (MHA, Merck, Germany) media. plates containing the discs were allowed to stand for at least $30 \mathrm{~min}$ before incubated at $37^{\circ} \mathrm{C}$ for $24 \mathrm{~h}$. Interpreting of the diameter of the zone of inhibition was done according to the protocol of the Clinical Laboratory Standard Institute (CLSI). ${ }^{13}$ Distilled water was used as negative control in all reactions.

\section{Statistical analysis}

All data were presented as mean \pm standard deviation (SD). SPSS. Ver. 20 was used for statistical analysis. Comparison of means were studied using the one-way ANOVA and also post hoc turkey test. Pvalue $\leq 0.05$ was determined as significant level. All tests were done 3 times.

\section{Results}

Table 1 represents the diameter of the zone of inhibition of different bacteria against methanoplic extract of M7 and M9 varieties of the G. max. Diameter of the inhibition zone of tested bacteria against different treatments of $G$. $\max$ had a ranges of $5.93 \pm 0.18$ to $22.61 \pm 1.80 \mathrm{~mm}$. M7 variety of the G. max had a higher antimicrobial effects on tested bacteria than M9 variety $(\mathrm{P}<0.05)$. The highest diameter of the zone of growth inhibition was seen for L. monocytogenes $(22.61 \pm 1.80 \mathrm{~mm})$ and $S$. aureus $(19.33 \pm 1.56 \mathrm{~mm})$ against methanolic extract of the M7 variety of $G$. $\max$ at concentration of $100 \mathrm{mg} / \mathrm{mL}$. Antimicrobial effects of the methanolic extract of the $G$. $\max$ was dose-dependent $(\mathrm{P}<0.05)$. Statistically significant differences were seen for the diameter of zone of the growth inhibition between different bacteria, different varieties and different concentrations

Table 1. Diameter of the zone of inhibition of different bacteria against methanoplic extract of G. max.

\begin{tabular}{|c|c|c|c|c|c|c|}
\hline Tested bacteria & $25 \mathrm{mg} / \mathrm{mL}$ & $\begin{array}{l}\text { thanolic ext } \\
\text { M7 variety } \\
50 \mathrm{mg} / \mathrm{mL}\end{array}$ & of $G . \max$, & $25 \mathrm{mg} / \mathrm{mL}$ & $\begin{array}{l}\text { tion (mm) } \\
\text { M9 variety } \\
50 \mathrm{mg} / \mathrm{mL}\end{array}$ & $100 \mathrm{mg} / \mathrm{mL}$ \\
\hline Bacillus cereus & $10.24 \pm 0.76^{\mathrm{Cb}}$ & $12.91 \pm 1.20^{\mathrm{Bb}}$ & $17.72 \pm 1.48^{\mathrm{Ac}}$ & $9.86 \pm 0.37^{\mathrm{Ca}}$ & $11.94 \pm 1.08^{\mathrm{Ba}}$ & $17.73 \pm 1.48^{\mathrm{Ab}}$ \\
\hline Staphylococcus aureus & $10.25 \pm 0.58^{\mathrm{Cb}}$ & $13.47 \pm 1.19^{\mathrm{Bb}}$ & $19.33 \pm 1.56^{\mathrm{Ab}}$ & $9.81 \pm 0.77^{\mathrm{Ca}}$ & $12.31 \pm 1.07 \mathrm{Ba}$ & $18.84 \pm 1.55^{\mathrm{Ab}}$ \\
\hline Listeria monocytogenes & $11.78 \pm 0.85^{\mathrm{Ea}}$ & $15.91 \pm 1.41^{\mathrm{Da}}$ & $22.61 \pm 1.80^{\mathrm{Aa}}$ & $10.21 \pm 0.71^{\mathrm{Ea}}$ & $13.45 \pm 1.29 \mathrm{Ca}$ & $20.01 \pm 1.44^{\mathrm{Ba}}$ \\
\hline Escherichia coli & $8.12 \pm 0.49^{\mathrm{Dc}}$ & $10.45 \pm 1.06^{\mathrm{Cc}}$ & $12.99 \pm 1.27^{\mathrm{Ad}}$ & $7.71 \pm 0.27^{\mathrm{Db}}$ & $8.98 \pm 0.54^{\mathrm{Cb}}$ & $10.21 \pm 0.54^{\mathrm{Bc}}$ \\
\hline Pseudomonas aeruginosa & & $4.32 \pm 0.21^{\mathrm{Bd}}$ & $6.70 \pm 0.42^{\mathrm{Ae}}$ & - & - & $4.63 \pm 0.21^{\mathrm{Bd}}$ \\
\hline Klebsiella pneumoniae & $9.93 \pm 0.75^{\mathrm{Cc}}$ & $11.21 \pm 1.03^{\mathrm{Bc}}$ & $14.33 \pm 1.17^{\mathrm{Ad}}$ & $7.12 \pm 0.47^{\mathrm{Db}}$ & $9.82 \pm 0.33^{\mathrm{Cb}}$ & $11.74 \pm 1.04^{\mathrm{Bc}}$ \\
\hline Salmonella typhi & $6.70 \pm 0.44^{\mathrm{Dd}}$ & $10.08 \pm 0.52^{\mathrm{Bc}}$ & $13.86 \pm 1.29^{\mathrm{Ad}}$ & $5.93 \pm 0.18 \mathrm{Dc}$ & $9.24 \pm 0.48^{\mathrm{Cb}}$ & $11.35 \pm 1.09 \mathrm{Bc}$ \\
\hline
\end{tabular}

Dissimilar capital letters in each row show significant differences about $\mathrm{P}<0.05$. Dissimilar small letters in each column show significant differences about $\mathrm{P}<0.05$.

Table 2. Diameter of the zone of inhibition of different bacteria against antibiotic agents.

\begin{tabular}{|c|c|c|c|c|c|}
\hline \multirow[t]{2}{*}{ Tested bacteria } & \multicolumn{5}{|c|}{ Diameter of zone of inhibition (mm) } \\
\hline & Cip5* & P10 & Tet30 & G10 & Az15 \\
\hline Bacillus cereus & $10.21 \pm 0.32^{\mathrm{Ac}}$ & $15.20 \pm 1.25^{\mathrm{Ac}}$ & $18.84 \pm 1.71^{\mathrm{Ac}}$ & $9.31 \pm 0.49^{\mathrm{Ac}}$ & $21.14 \pm 1.938^{\mathrm{Ac}}$ \\
\hline Staphylococcus aureus & $14.48 \pm 1.38^{\mathrm{Ab}}$ & $18.71 \pm 1.62^{\mathrm{Ab}}$ & $13.22 \pm 1.19^{\mathrm{Ab}}$ & $14.27 \pm 1.36^{\mathrm{Ab}}$ & $20.82 \pm 1.97^{\mathrm{Ab}}$ \\
\hline Listeria monocytogenes & $9.12 \pm 0.63$ & $23.94 \pm 2.03^{\text {Aa }}$ & $20.55 \pm 1.95^{\mathrm{Aa}}$ & $9.03 \pm 0.65^{\mathrm{Aa}}$ & $24.95 \pm 2.11^{\mathrm{Aa}}$ \\
\hline Escherichia coli & $10.57 \pm 1.34^{\mathrm{Ad}}$ & $10.65 \pm 0.59^{\text {Ad }}$ & $11.42 \pm 1.36^{\mathrm{Ad}}$ & $11.77 \pm 1.14^{\mathrm{Ad}}$ & $14.17 \pm 1.30^{\mathrm{Ad}}$ \\
\hline Pseudomonas aeruginosa & $7.12 \pm 0.38^{\mathrm{Ae}}$ & $6.57 \pm 0.38^{\mathrm{Ae}}$ & $5.94 \pm 0.38^{\mathrm{Ae}}$ & $8.15 \pm 0.72^{\mathrm{Ae}}$ & $10.94 \pm 1.08^{\mathrm{Ae}}$ \\
\hline Klebsiella pneumoniae & $15.71 \pm 1.46^{\mathrm{Ad}}$ & $13.21 \pm 1.22^{\mathrm{Ad}}$ & $12.79 \pm 1.20^{\mathrm{Ad}}$ & $12.82 \pm 1.14^{\mathrm{Ad}}$ & $18.48 \pm 1.63^{\operatorname{Ad}}$ \\
\hline Salmonella typhi & $14.19 \pm 1.23^{\mathrm{Ad}}$ & $11.43 \pm 1.36^{\mathrm{Ad}}$ & $11.55 \pm 1.07^{\mathrm{Ad}}$ & $11.21 \pm 1.44^{\mathrm{Ad}}$ & $15.52 \pm 1.43^{\mathrm{Ad}}$ \\
\hline
\end{tabular}

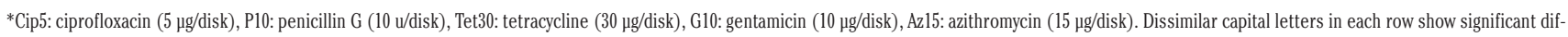
ferences about $\mathrm{P}<0.05$. Dissimilar small letters in each column show significant differences about $\mathrm{P}<0.05$. 
$(\mathrm{P}<0.05)$. Table 2 represents the diameter of zone of the growth inhibition of tested bacteria against different antibiotic agents. Diameter of the inhibition zone of tested bacteria against different antibiotic agents had a ranges of $5.94 \pm 0.38$ to $24.95 \pm 2.11$ $\mathrm{mm}$. Ciprofloxacin, penicillin G tetracycline, gentamicin and azithromycin antibiotic agents exhibited the highest diameter of zone of the growth inhibition for K. pneumoniae $(15.71 \pm 1.46 \mathrm{~mm})$, L. monocytogenes $(23.94 \pm 2.03 \mathrm{~mm})$, L. monocytogenes $(20.55 \pm 1.95 \mathrm{~mm}), S$. aureus $(14.27 \pm 1.36$ $\mathrm{mm})$ and L. monocytogenes $(24.95 \pm 2.11$ $\mathrm{mm})$, respectively. Statistically significant difference was seen for the diameter of the inhibition zone of tested bacteria between different antibiotics $(\mathrm{P}<0.05)$.

\section{Discussion}

Findings of the current research revealed that methanolic extract of G. $\max$ and especially its M7 variety had significant antimicrobial effects on tested bacteria and especially $L$. monocytogenes, B. cereus, E. coli, S. aureus and K. pneumonia. We found that inhibition zone of growth $B$. cereus, $S$. aureus, L. monocytogenes, E. coli, $P$. aeruginosa, $K$. pneumonia and $S$. typhi against methanolic extract of the M7 variety of $G$. $\max$ at concentration of $100 \mathrm{mg} / \mathrm{mL}$ were $17.72 \pm 1.48, \quad 19.33 \pm 1.56, \quad 22.61 \pm 1.80$, $12.99 \pm 1.27,6.70 \pm 0.42,14.33 \pm 1.17$ and $13.86 \pm 1.29 \mathrm{~mm}$ respectively. Inhibitory effects of the methanolic extract of the M7 variety of $G$. $\max$ at concentration of 100 $\mathrm{mg} / \mathrm{mL}$ were higher than some tested antibiotic agents.

One possible explanation for the high antimicrobial effects of methanolic extract of G. $\max$ is the fact that G. $\max$ is full from antimicrobial chemical components. G. $\max$ is a rich source of phenols, saponins, micronutrients, flavonoids, and polysaccharides which may be responsible for its high antimicrobial effects. ${ }^{14}$ Phenolic compounds are well known to have a negative effect on the growth of bacteria through inhibiting their nucleic acid synthesis, enzymatic activity, cytoplasmic membrane function and energy metabolism. ${ }^{15}$ Isoflavones is one of the main chemical components of the G. max extract. Isoflavones have many biological effects including antimicrobial action. Wang et al. (2010) ${ }^{16}$ showed that soybean isoflavones inhibited the nucleic acid synthesis of $S$. aureus. In addition, phenolic acids were found at significant concentrations and their antimicrobial activity has been widely investigated. Alves et al. $(2013)^{17}$ and Saavedra et al. $(2010)^{18}$ showed that syringic, coumaric, ferullic and vanillic acids which were found in the $G$. max extract exhibited significant antimicrobial activity against both Gram-positive and Gram-negative bacteria. Therefore, the antibacterial activity detected in our research could be explained by the pool of phenolic compounds found in our extract and also large amount of isoflavones.

We found that Gram-positive bacteria were more susceptible against G. max than Gram-negative bacteria. This part of our research is consistent with findings of Villalobos et al. (2016). ${ }^{14}$ They showed that among tested bacteria, the highest antimicrobial activity was observed against L. monocytogenes, B. cereus and E. faecalis, with values around $50 \%$ inhibition even at the lowest concentration assayed. This is may be due to the assumption that Gram-negative bacteria are more resistant to antimicrobial compounds due to their outer lipopolysaccharide membranes. Nevertheless, this was not always true for all strains assayed, for example $K$. pneumoniae was inhibited by the G. max extract in our study. Ghahari et al. (2017) ${ }^{19}$ reported that the essential oil of soybean seeds showed maximum activity against $S$. aureus [Minimum Inhibitory concentration (MIC) of $50 \mu \mathrm{g} / \mathrm{L}$ ], B. subtilis and E. coli (MIC of $100 \mu \mathrm{g} / \mathrm{mL}$ ). They showed no inhibition for $P$. aeruginosa with the highest concentration. The lower susceptibility of Gram-negative bacteria to extracts may be explained in terms of diffusion limitations of essential compounds, through their external membrane, owing to the presence of a hydrophilic barrier. Although this barrier is not totally impermeable, it however hinders the transport of macromolecules and hydrophobic components. Kumaran and Citarasu $(2015)^{20}$ reported that zone of the growth inhibition of crude and pure extract of G. max against B. subtilis, E. coli, Vibrion harvey ( $V$. harvey), Aeromonase hydrophila (A. hydrophila) and V. patahaemolyticus were $14.07 \pm 1.20$ and $15.54 \pm 0.5 \mathrm{~mm}, 9.05 \pm 0.5$ and $13.17 \pm 0.2$ $\mathrm{mm}, 8.02 \pm 0.6$ and $16.07 \pm 0.8 \mathrm{~mm}, 9.47 \pm 0.2$ and $14.32 \pm 0.2 \mathrm{~mm}$ and $10.84 \pm 0.6$ and $15.49 \pm 0.7 \mathrm{~mm}$, respectively. They showed that high presence of saponin is the main factor for the high antimicrobial activities of G. max. Kumaran and Citarasu (2015) ${ }^{21}$ reported that zone of the growth inhibition of $1 \mathrm{~g} / \mathrm{mL}, 2 \mathrm{~g} / \mathrm{mL}$ and $3 \mathrm{~g} / \mathrm{mL}$ concentrations of the G. nax against E. coli, P. aeruginosa and $V$. harvey were 4.2, 5.9 and 2.7 $\mathrm{mm}, 3.8,5.4$ and $1.4 \mathrm{~mm}$ and 5.4, 6.1 and $1.8 \mathrm{~mm}$, respectively.

Unauthorized and indiscriminate prescription of antibiotics and especially tetracycline, penicillin, gentamicin and ciprofloxacin in medicine and veterinary are the main reasons for the high prevalence of resistance (low zone of inhibition) in the bacterial strains of our study. In fact, the methanolic extract of G. max harbored the higher antimicrobial effects than mentioned antibiotics.

\section{Conclusions}

In conclusion, we identified a considerable antimicrobial effects of the methanolic extracts of M7 and M9 varieties of G. $\max$ against pathogenic bacteria and especially Gram-positive bacteria. M7 variety had a higher antimicrobial effects than M9. Highest in herbivory effects of the M7 variety of G. max extract was seen for L. monocytogenes, B. cereus, S. aureus and K. pneumonia. Antimicrobial effects of $G$. $\max$ extract were dose-depended and the highest antimicrobial effects was seen for the 100 $\mathrm{mg} / \mathrm{mL}$ concentration. Judicious prescription of antibiotics can control and eliminate the occurrence of antibiotic resistance in pathogenic bacteria. We recommended the production of antibiotic agent using the methanolic extract of the M7 variety of the G. $\max$.

\section{References}

1. Dehkordi FS, Yazdani F, Mozafari J, et al. Virulence factors, serogroups and antimicrobial resistance properties of Escherichia coli strains in fermented dairy products. BMC Res Notes 2014;7:217.

2. Dormanesh B, Safarpoor Dehkordi F, Hosseini S, et al. Virulence factors and o-serogroups profiles of uropathogenic Escherichia coli isolated from Iranian pediatric patients. Iran Red Crescent Med J 2014;16:e14627.

3. Ranjbar R, Masoudimanesh M, Safarpoor Dehkordi F, et al. Shiga (Vero)-toxin producing Escherichia coli isolated from the hospital foods; virulence factors, o-serogroups and antimicrobial resistance properties. Antimicrob Resist Infect Control 2017;6:4.

4. Momtaz H, Safarpoor Dehkordi F, Rahimi E, et al. Virulence genes and antimicrobial resistance profiles of Staphylococcus aureus isolated from chicken meat in Isfahan province, Iran. J Appl Poult Res 2013;22:913-21.

5. Safarpoor Dehkordi F, Barati S, Momtaz H, et al. Comparison of shedding and antibiotic resistance properties of Listeria monocytogenes isolated 
from milk, feces, urine and vaginal secretion of bovine, ovine, caprine, buffalo and camel species in Iran. Jundishapur J Microbiol 2013;6:28494.

6. Kidd TJ, Mills G, Sá-Pessoa J, et al. A Klebsiella pneumoniae antibiotic resistance mechanism that subdues host defences and promotes virulence. EMBO Mol Med 2017;9:430-47.

7. Pappa O, Vantarakis A, Galanis A, et al. Antibiotic resistance profiles of Pseudomonas aeruginosa isolated from various Greek aquatic environments. FEMS Microbiol Ecol 2016;92:fiw086.

8. Owusu-Kwarteng J, Wuni A, Akabanda $\mathrm{F}$, et al. Prevalence, virulence factor genes and antibiotic resistance of Bacillus cereus sensu lato isolated from dairy farms and traditional dairy products. BMC Microbiol 2017;17:65.

9. Mirkamandar E, Shakibaie MR, Adeli S. et al. In vitro antimicrobial activity of Salvadora persica extract on Helicobacter pylori strains isolated from duodenal ulcer biopsies. Microbiol Res 2012;3.

10. Carroll BJ, McNeil DL, Gresshoff PM. Isolation and properties of soybean [Glycine $\max ($ L.) Merr.] mutants that nodulate in the presence of high nitrate concentrations. Proc Natl Acad Sci USA 1985;82:4162-6.

11. Malenčić D, Cvejić J, Miladinović J. Polyphenol content and antioxidant properties of colored soybean seeds from Central Europe. J Med Food 2012;15:89-95.

12. Villalobos Mdel C, Serradilla MJ, Martín A, et al. Antioxidant and antimicrobial activity of natural phenolic extract from defatted soybean flour byproduct for stone fruit postharvest application. J Sci Food Agric 2016;96:2116-24

13. Clinical and Laboratory Standards Institute (CLSI). Performance standards for antimicrobial susceptibility testing. Twenty-Fifth Informational Supplement M100-S25. Wayne Pa, 2015.

14. Villalobos MDC, Serradilla MJ, Martín $\mathrm{S}$, et al. Antioxidant and antimicrobial activity of natural phenolic extract from defatted soybean flour by-product for stone fruit postharvest application. J Sci Food Agric 2016;96:2116-24.

15. Tim TP, Lamb AJ. Antimicrobial activity of flavonoids. Int $\mathrm{J}$ Antimicrob Agents 2005;26:343-56.

16. Wang Q, Wang H, Xie M. Antibacterial mechanism of soybean isoflavone on
Staphylococcus aureus. Arch Microbiol 2010:192;893-8.

17. Alves MJ, Ferreira ICFR, Froufe HJC, et al, Antimicrobial activity of phenolic compounds identified in wild mushrooms, SAR analysis and docking studies. J Appl Microbiol 2013;115:346-57.

18. Saavedra MJ, Borges A, Dias C, et al. Antimicrobial activity of phenolics and glucosinolate hydrolysis products and their synergy with streptomycin against pathogenic bacteria. Med Chem 2010;6:174-83.

19. Ghahari S, Alinezhad H, Nematzadeh $\mathrm{GA}$, et al. Chemical composition, antioxidant and biological activities of the essential oil and extract of the seeds of Glycine max (Soybean) from North Iran. Curr Microbiol 2017;74:522-31.

20. Kumaran T, Gitarasu T. Isolation, characterization and antibacterial activity of crude and purified saponin extract from seeds of soyabean (Glycine Max). Int J Pure Appl Res 2015;1:33-6.

21. Kumaran T, Gitarasu T. Phytochemical screening, bioautography and antibacterial evaluation of the methanolic extract of Glycine max (Soybean). Global J Med Publ Health 2015;4:1-7. 